\title{
O Método dos Vapores Metálicos
}

\author{
J O Ã L UÍS A. FERREIRA D A S L V A *
}

\section{1 - INTRODUÇÃO}

Um dos processos mais recentes para aumentar a reactividade de metais com substratos orgânicos, de forma a permitir a obtenção de melhores rendimentos, é o Método dos Vapores Metálicos (Metal Vapour Synthesis - MVS). Este método consiste em vaporizar metal em vácuo e co-condensá-lo com o vapor do substrato na superfície arrefecida do vaso reaccional (Figura 1). A difusão e a reacção dos átomos metálicos assim formados com as moléculas orgânicas, durante o aquecimento do vaso reaccional até à temperatura ambiente, produz a formação de novas espécies, geralmente complexos organometálicos.

Esta técnica principiou a ser utilizada em 1969 por Timms, que preparou os complexos $\left[\mathrm{Cr}\left(\eta^{6-} \mathrm{C}_{6} \mathrm{H}_{6}\right)_{2}\right]$, bis(benzeno)crómio (Equação 1), e $\left[\mathrm{Fe}\left(\eta^{5}-\mathrm{C}_{5} \mathrm{H}_{5}\right)_{2}\right]$, ferroceno, por co-condensação dos vapores dos respectivos metais com benzeno ou ciclopentadieno [1].

Estes complexos já tinham anteriormente sido sintetizados por métodos convencionais.

O número actual de reacções efectuadas por MVS é já bastante grande. Esta técnica e as suas aplicações são discutidas em dois livros [2,3] e também em vários artigos de revisão [4 - 10].

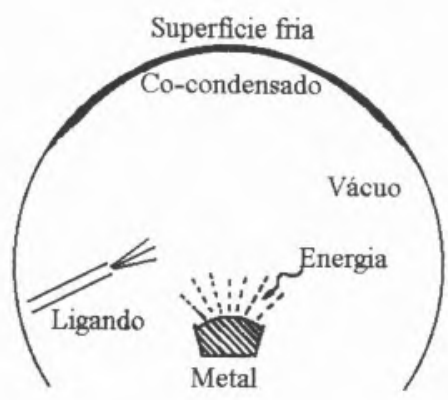

Fig. 1 - Descrição esquemática do Método dos Vapores Metálicos

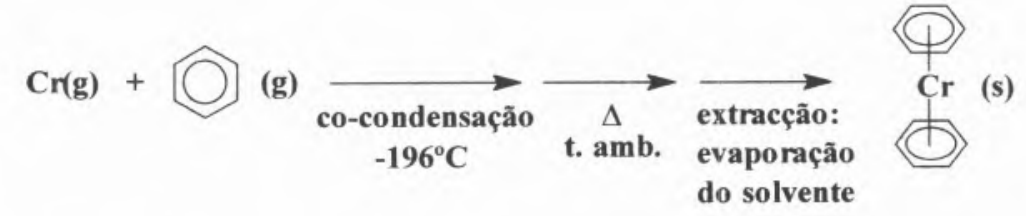

(1)

\section{2 - EQUIPAMENTO}

O Método dos Vapores Metáli$\cos$ necessita de equipamentos relativamente complexos, que permitam a evaporação simultânea de metais (com temperaturas de vaporização que vão desde $153^{\circ} \mathrm{C}$ para o Césio, até $3309^{\circ} \mathrm{C}$ para o Tungsténio) e de ligandos orgânicos, bem como a sua co-condensação a baixas temperatu-

dois andares e elevado caudal e por uma bomba de alto vácuo; os primeiros reactores utilizavam bombas difusoras mas os mais recentes recorrem a criobombas ou bombas turbomoleculares, que têm a vantagem de não contaminar o sistema com óleo [11].

A superfície reaccional é, em geral, a superfície interna do reactor. A superfície exterior do balão é arre-

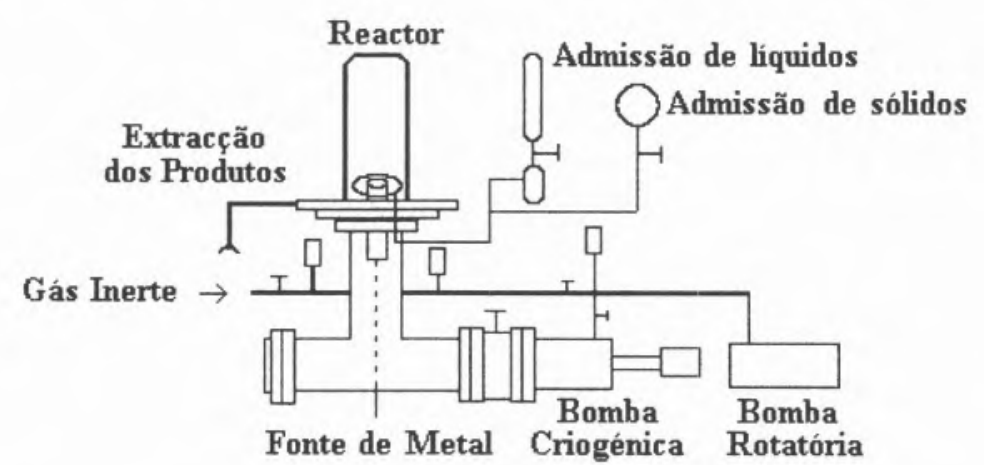

Fig. 2 - Equipamento para MVS

ras e o seu isolamento em atmosfera inerte (uma vez que a grande maioria dos produtos formados são instáveis ao oxigénio do ar).

Os componentes fundamentais de um equipamento de vapores metálicos são a superfície reaccional (ou reactor), a fonte de átomos metálicos, os sistemas de admissão de substrato e de extracção de produtos, e o sistema de vácuo (Figura 2).

O sistema de vácuo destina-se a criar no interior do reactor uma pressão suficientemente baixa para garantir que o livre percurso médio de colisão dos átomos e das moléculas de substrato é superior ao raio do reactor, assegurando, assim, que não se dão reaç̧ões secundárias enquanto as espécies se encontram a caminho da superfície reaccional. É constituído por uma bomba rotatória de fecida, quase sempre com azoto líquido, para promover a co-condensação do metal e do ligando. Os reactores mais utilizados são balões de vidro (ou metal), cilíndricos ou esféricos.

Os balões cilíndricos constituem os reactores estáticos e a evaporação do metal e do ligando dá-se no centro do reactor, de um modo radial $[2,8]$ (Figura 3).

Os balões esféricos são utilizados nos reactores rotativos, em que o balão se encontra animado de um movimento de rotação, sendo o metal e o ligando evaporados em direcções diametralmente opostas (Figura 4). A principal vantagem da utilização deste tipo de reactores reside no facto de eles tornarem praticamente impossível a interacção dos átomos do metal com as moléculas 


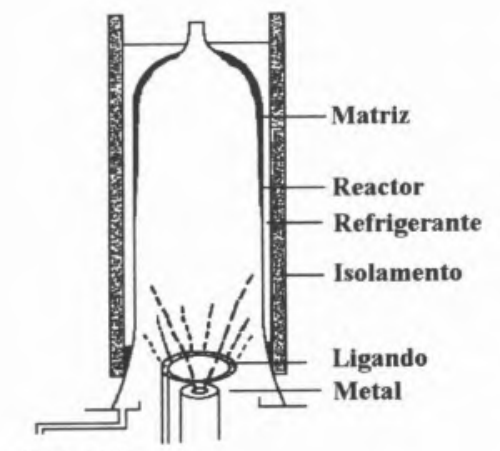

Extracção

Extracção
de produtos

Fig. 3 - Reactor estático

do ligando ao longo do trajecto até às paredes do reactor, onde co-condensam e reagem devido à rotação do balão. Contudo, apresentam como desvantagem a facilidade com que se desenvolvem fugas no selo rotatório de vácuo.

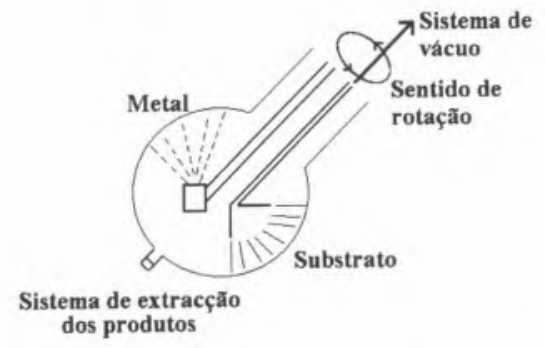

Fig. 4 - Reactor rotatório

Os reactores rotatórios podem igualmente ser utilizados para efectuar reacções entre átomos metálicos e soluções de ligandos pouco voláteis em solventes inertes, como o isopentano ou o metilciclohexano $[2,4]$. Neste caso, grande parte da solução mantém-se no fundo do reactor. No entanto, como resultado da rotação (a uma velocidade 60-100 rpm), cria-se um filme de solução na parte superior do reactor, onde o vapor metálico está a ser depositado. A reacção dá-se entre este filme de solução e o vapor metálico.

O sistema de admissão de ligando varia segundo o tipo de ligandos que se pretende introduzir no reac-

tor. Para ligandos líquidos consiste num sistema de ampolas colocado acima do nível do reactor, que conduz o ligando por gravidade até à câmara em que é vaporizado. No caso de ligandos sólidos sublimáveis resume-se a um balão aquecido por uma manta. Em ambos os casos a entrada no reactor é feita por um sistema de tubuladuras, aquecido para evitar a condensação do ligando, e controlado por válvulas micrométricas. O dispositivo de dispersão do ligando na superfície do reactor pode ser um anel ou um cone, consoante a geometria do reactor (ver Figuras 3 e 4).

Os principais tipos de fontes utilizados são o canhão de electrões e as fornalhas de resistência de molibdénio ou tungsténio revestidas a alumina, podendo também utilizar-se lasers ou filamentos aquecidos [2].

Com fornalhas de alumina ( $\mathrm{Fi}$ gura 5) é possível evaporar $\mathrm{Mg}, \mathrm{Cr}$, $\mathrm{Mn}, \mathrm{Fe}, \mathrm{Co}, \mathrm{Ni}, \mathrm{Cu}, \mathrm{Ag}, \mathrm{Zn}, \mathrm{Cd}$ e $\mathrm{Al}$ [2] em quantidades até $50 \mathrm{~g} /$ hora. Neste caso o metal mais electropositivo que se consegue evaporar é o crómio, visto que, com o aumento de carácter electropositivo aumenta também o ataque químico à alumina.
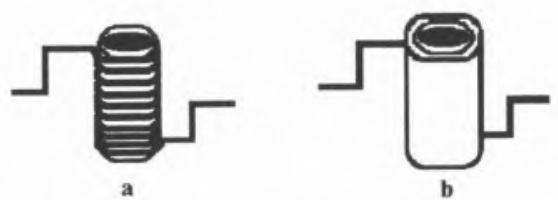

Fig. 5 - a) Enrolamento de tungsténio em torno de um cadinho; b) Cadinho revestido com alumina

Foi com um reactor estático equipado com uma fornalha constituída por um cadinho de alumina, envolvido por um enrolamento de fio de tungsténio e arrefecido a água (Figura 6) que Timms, tal como acima referido, efectuou a síntese do bis(benzeno)crómio a partir da co-condensação de benzeno e vapor de crómio [1]. Este reactor encontrase comercializado pela Kontes-Martin Glass Company [12] e destina-se não só à pesquisa como também, pela sua facilidade de utilização, à execução de trabalhos de laboratório de estu-

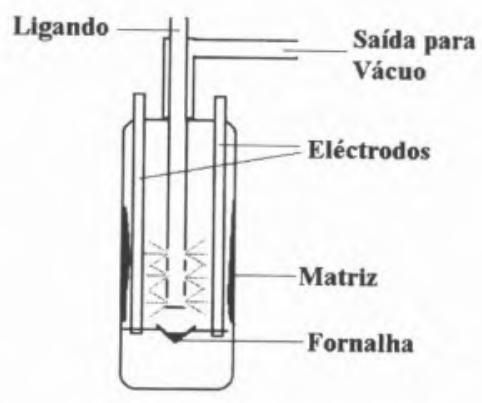

Fig. 6 - Reactor estático com fornalha

dantes de licenciatura, tendo sido utilizado por alunos da Universidade de Bristol com bons resultados [13].

O método mais conveniente para alargar o espectro de metais evaporáveis, bem como aumentar a sua velocidade de evaporação, é a utilização de um canhão de electrões. Este dispositivo permite vaporizar mesmo os metais mais refractários, como foi demonstrado por Green com a síntese dos bis-arenos de molibdénio [8] , a partir do metal e de benzeno, tolueno e mesitileno.

Os electrões são obtidos por aquecimento de um filamento de tungsténio através da passagem de uma corrente eléctrica, e acelerados para um núcleo central de cobre pelo estabelecimento de uma diferença de potencial elevada (entre 3 e 10 $\mathrm{kV}$ ) entre esse núcleo, que se encontra a um potencial positivo, e os restantes elementos do canhão. O núcleo é arrefecido a água e, no seu topo, encontra-se o metal a evaporar; o choque dos electrões com a superfície do metal aquece-a, vaporizando o metal. Os átomos metálicos passam para a câmara da reacção através de um orifício no escudo reflector, que foca os electrões no metal (Figura 7).

Utilizando um canhão deste tipo, com uma fonte de tensão de 10 kW, é possível evaporar $\mathrm{Nb}, \mathrm{Ta}, \mathrm{Zr}$, Os e Re, bem como sintetizar $20 \mathrm{~g} / \mathrm{dia}$ de bis(tolueno)titânio ou $5 \mathrm{~g} /$ dia de bis-arenos de tungsténio [2]. Torna-se assim possível obter produtos em quantidades suficientes para efectuar estudos detalhados sobre as suas reactividades. 


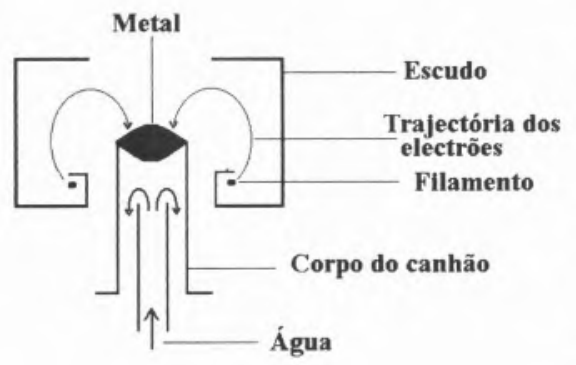

Fig. 7 - Canhão de electrões

A obtenção de um bom vácuo é particularmente importante para quem utilize como fonte de átomos metálicos um canhão de electrões, porque neste dispositivo ocorrem descargas eléctricas de alta tensão entre os seus componentes a diferentes potenciais, sempre que a pressão é superior a $5 \times 10^{-5} \mathrm{mbar}$.

\section{3 - DESCRIÇÃO DO MÉTODO EXPERIMENTAL}

Uma reacção típica de MVS principia pela montagem do reactor com o metal e o ligando colocados nas respectivas fontes, seguida da evacuação do aparelho. Após atingida a pressão pretendida, o reactor é arrefecido com azoto líquido. Ao atingir uma temperatura suficientemente baixa para condensar o ligando principia-se a evaporação simultânea do metal e do ligando. Quando se pretende dar por concluída a reacção interrompe-se a evaporação, isola-se o reactor, que se enche com um gás inerte, e desliga-se o sistema de vácuo. Deixa-se a superfície do reactor atingir a temperatura ambiente, período durante o qual os átomos de metal e as moléculas de ligando irão reagir sobre a superfície interna do reactor. O produto obtido é extraído por gravidade, com o recurso a um solvente de lavagem, seguindo-se a sua purificação. Todas as operações a partir da extracção recorrem a técnicas de trabalho em atmosferas inertes (azoto, argon, etc), quer em linhas de vácuo, quer em caixas de luvas $[14,15]$.

\section{4 - VANTAGENS DO MÉTODO DOS VAPORES METÁLICOS}

As vantagens do método dos vapores metálicos sobre os processos de síntese convencional são de dois tipos:

\section{1 - Vantagens termodinâmicas e cinéticas:}

Como já foi referido este método permite obter por uma reacção num só passo produtos que por outras vias são obtidos em rendimentos muito reduzidos, ou mesmo impossíveis, de sintetizar. Por exemplo, o MVS é a única via possível para a síntese dos bis-naftalenos de Ti, V, Cr e Mo[2]. Noutros casos, como para o bis(benzeno)tungsténio, o rendimento obtido $(40 \%)$ é muito superior ao conseguido pelo processo Fischer-Hafner, através da redução de sais com alumínio $(2 \%)$, reduzindo-se igualmente o tempo de preparação de cerca de 2 a 3 semanas de trabalho para 2 dias. A razão para estes melhoramentos prendem-se com as vantagens cinéticas e termodinâmicas do método, ilustradas na Figura 8.

Embora o diagrama representado nesta figura seja qualitativo e simplificado é possível ver que cine- ticamente a reacção nas condições de MVS

$$
\mathrm{M}(\mathrm{g})+\mathbf{n L}(\mathrm{g}) \longrightarrow \mathrm{ML}_{\mathbf{n}}(\mathrm{s})
$$

é mais favorável uma vez que a sua energia de Gibbs de activação, $\Delta G \neq$ (mvs), é menor do que a correspondente energia para a reacção em solução, $\Delta \mathrm{G} \ddagger$ (sol.), partindo do metal no estado sólido.

$$
\mathrm{M}(\mathrm{s})+\mathrm{nL}(\mathrm{I}) \longrightarrow \mathrm{ML}_{\mathrm{n}}(\mathrm{sol})
$$

Este facto é facilmente explicável com base na fácil coordenação dos ligandos ao átomo isolado para formarem o estado de transição. Por outro lado a reacção na fase gasosa é igualmente favorecida termodinamicamente uma vez que o valor de $\Delta_{\mathrm{r}} \mathrm{G}$ (mvs) é maior em valor absoluto do que o de $\Delta_{\mathrm{r}} \mathrm{G}$ (sol.). Em ambos os casos as diferenças registadas são aproximadamente iguais ao $\Delta_{\text {sub }} G$ do metal. Quanto maior a energia de Gibbs de sublimação do metal, maior vantagem se obtém por utilização de MVS. Para o tungsténio, por exemplo, $\Delta_{\text {sub }} G_{m}^{o}=807.3 \mathrm{~kJ} / \mathrm{mol}$ [16].

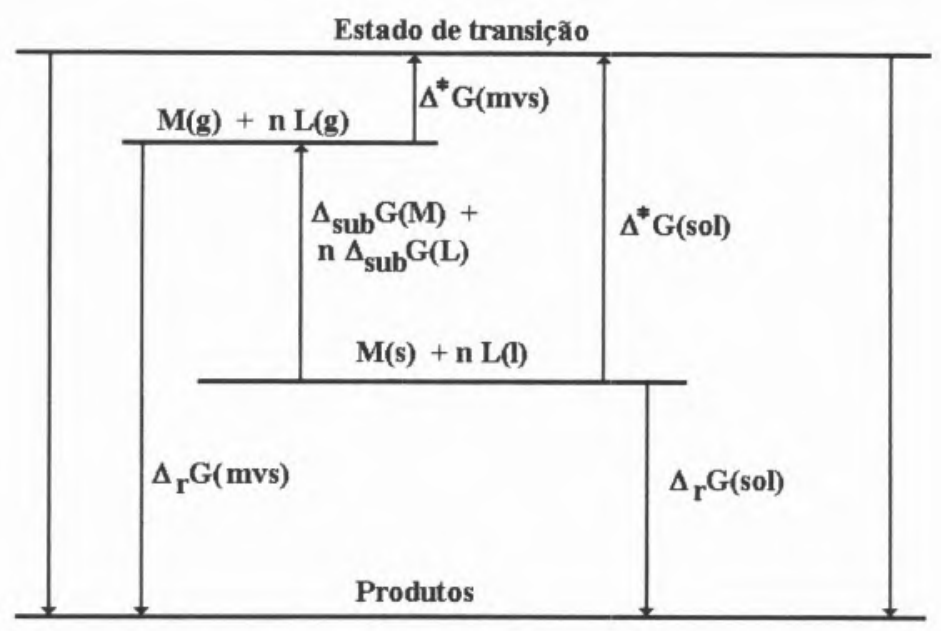

Fig. 8 - Comparação energética entre MVS e processos convencionais 


\section{2 - Vantagens técnicas}

Enquanto que as reacções em solução ocorrem muitas vezes em vários passos, exigindo operações de transferência e purificação intermédias, as reacções por MVS dão-se num só passo, o que as torna mais simples de executar.

Os produtos formados estão sujeitos a controle termodinâmico, formando-se apenas o mais estável. Este facto, aliado a que a maior parte dos metais vaporizam sob a forma de átomos e não de agregados poliatómicos e se encontram no estado fundamental (uma vez que os estados excitados têm tempos de vida muito curtos) faz com que geralmente de cada reacção resulte apenas um produto. Esta regra apresenta como grandes excepções
A natureza monoatómica do vapor metálico permite ainda eliminar completamente alguns problemas encontrados com as reacções com metais no estado sólido, como a baixa superfície de contacto e também a existência de óxidos à superfície do metal.

A utilização de baixas temperaturas (geralmente $77 \mathrm{~K}$ ) para condensar os vapores do metal e do ligando facilita igualmente o isolamento de complexos termicamente instáveis.

\section{5 - POSSÍVEIS REACÇÕES ENTRE ÁTOMOS METÁLICOS E SUBSTRATOS}

As principais reacções que podem ocorrer na co-condensação

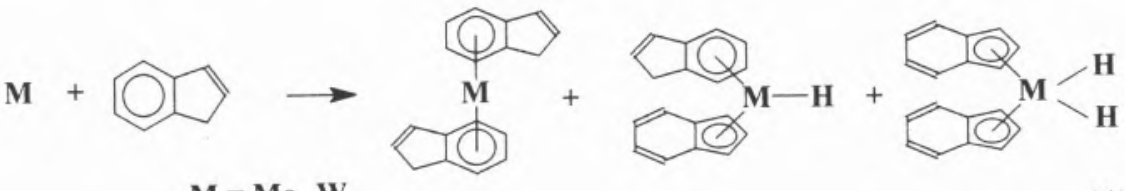

$$
\mathbf{M}=\mathbf{M o}, \mathbf{W}
$$

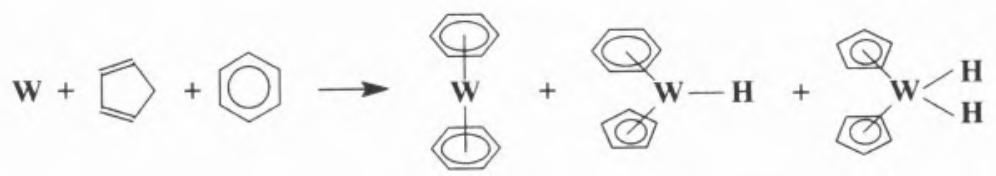

os casos da possibilidade de obtenção de isómeros com estabilidades semelhantes (Equação 4) ou da utilização de misturas de ligandos (Equação 5) [2]. de um átomo de metal de transição e moléculas de substratos orgânicos são a adição ou coordenação simples, a adição oxidativa e reacções redox ou de transferência de electrões.

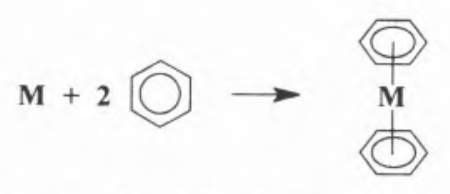

$\mathrm{M}=\mathrm{Sc}, \mathrm{Ti}, \mathrm{Zr}, \mathrm{Hf}, \mathrm{V}, \mathrm{Nb}, \mathrm{Ta}, \mathrm{Cr}, \mathrm{Mo}, \mathrm{W}$ e lantanídeos

$$
\mathrm{M}+\mathrm{nPF}_{3} \longrightarrow \mathrm{M}\left(\mathrm{PF}_{3}\right)_{\mathrm{n}}
$$

$M=C r, M o, n=6 ; M=F e, n=5 ; M=N i, P d, n=4$
A coordenação simples dá-se quando o ligando se coordena ao metal sem que haja alteração no seu estado de oxidação.

Os exemplos mais conhecidos deste tipo de reacção são a preparação de bis-arenos de metais de transição (Equação 6) e a reacção de átomos metálicos com fosfinas (Equação 7) [2].

$\mathrm{Na}$ adição oxidativa a coordenação do ligando dá-se com aumento do estado de oxidação do metal.

$$
\mathrm{M}+\mathrm{nRX} \longrightarrow \mathrm{MR}_{\mathbf{n}} \mathrm{X}_{\mathrm{n}}
$$

Para tal, é necessário que o átomo metálico disponha de, pelo menos, duas posições de coordenação livres e de electrões $\underline{d}$ não ligantes, condições estas que, como é fácil de ver, são inteiramente obedecidas por átomos isolados de metais de transição. São exemplo deste tipo as reacções de Mo e W com ciclopentadieno (Equação 9) e as reacções entre átomos de metais de transição e halogenetos orgânicos (Equação 8, $\mathrm{R}=$ radical orgânico, p.ex. alquilo, $\mathrm{X}=$ halogeneto ) [2].

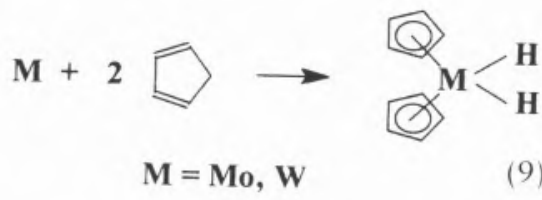

Uma aplicação muito importante deste tipo de reacções é a síntese de Reagentes de Grignard (Equação $10)$, com rendimentos muito superiores aos obtidos por síntese convencional, envolvendo magnésio activado [2].

$$
\mathrm{Mg}+\mathrm{n}-\mathrm{PrI} \longrightarrow \underset{(76 \%)}{\mathrm{n}-\mathrm{PrMgI}}\left(\begin{array}{c}
76 \% \\
(1)
\end{array}\right.
$$

Nas reacções redox (Equação 11) há transferência de electrões do metal para o ligando.

$$
\mathrm{M}+\mathrm{nAB} \longrightarrow \mathrm{M}^{\mathrm{n}+}\left(\mathrm{AB}^{-}\right)_{\mathrm{n}}
$$


Como exemplo desta reacção tem-se a formação de $\left[\mathrm{M}^{3+}(\mathrm{t}-\mathrm{BuDAB})_{3}\right]$ a partir de átomos de Ti,Y, Nd, Sm e Yb e t-BuDAB (t-butildiazabutadieno $=\mathrm{t}-\mathrm{Bu}-\mathrm{N}=\mathrm{CH}-\mathrm{CH}=\mathrm{N}-\mathrm{t}-\mathrm{Bu}$, ligando bidentado, que se coordena pelos dois átomos de azoto) [9].

\section{6 - APLICAÇÕES DO MÉTODO DOS VAPORES METÁLICOS}

\section{1 - Síntese de complexos organometálicos}

Embora já tenham sido citados bastantes exemplos de sínteses de complexos organometálicos por MVS, será ainda conveniente referir alguns outros, como a síntese de complexos com heterociclos (Equação 12) [2], a síntese de bis(benzotiofenos), complexos estes que podem ser utilizados como modelos para estudos de desulfuração do petróleo (Equação 13), e a síntese de complexos sanduiche com dois átomos metálicos e três anéis benzénicos (Equação 14) [10].

Um caso particular deste tipo de aplicação é a preparação de compostos de partida para a síntese de novos complexos organometálicos; como exemplo principal deste tipo de utilização pode citar-se a síntese dos bis(naftalenos) de Ti, V, Cr e Mo, já referida na introdução (Equação 15). Estes compostos só podem ser obtidos através de MVS, uma vez que a aplicação do método de Fischer-Hafner ao naftaleno resulta na sua parcial hidrogenação [2].

Os bis(naftalenos) de $\mathrm{Ti}, \mathrm{V}, \mathrm{Cr}$ e Mo constituem excelentes compostos de partida para reacções de substituição, em especial na preparação de complexos mononaftalénicos (Equação 16).

\section{2 - Preparação de "lamas" reactivas de metais de transição}

O Método dos Vapores Metálicos pode ser utilizado para produzir metal, finamente dividido, numa forma particularmente activa. A co-condensação de átomos metálicos com solventes "inertes" conduz à for-

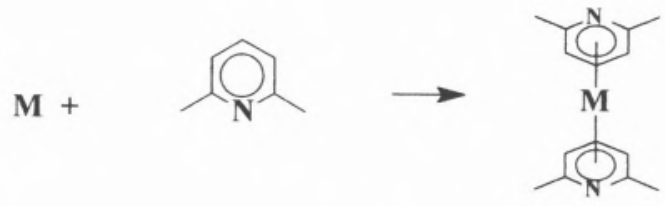

$\mathrm{M}=\mathrm{Ti}, \mathrm{V}, \mathrm{Cr}$ e Mo

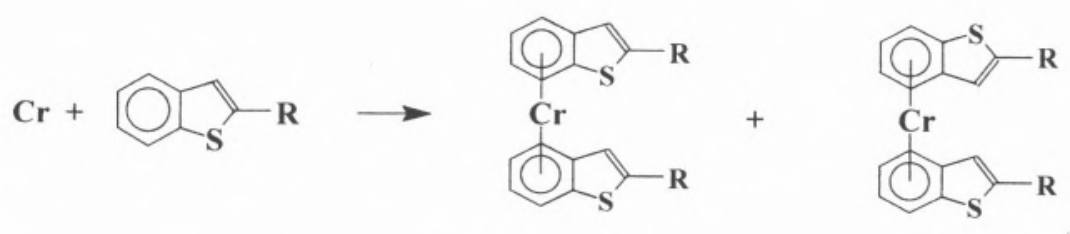

$\mathrm{R}=\mathrm{H}, \mathrm{CH}_{3}, \mathrm{Si}\left(\mathrm{CH}_{3}\right)_{3}$

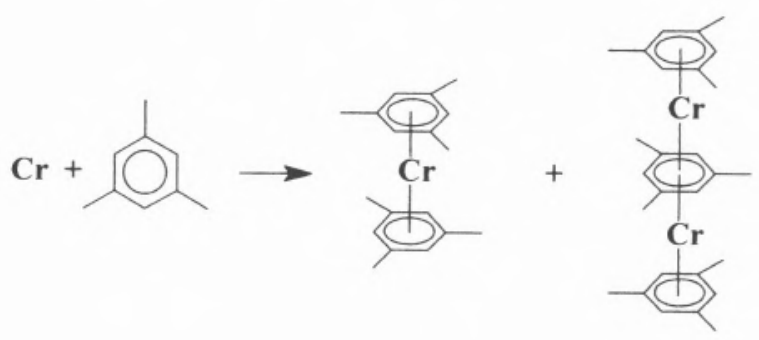

(14)

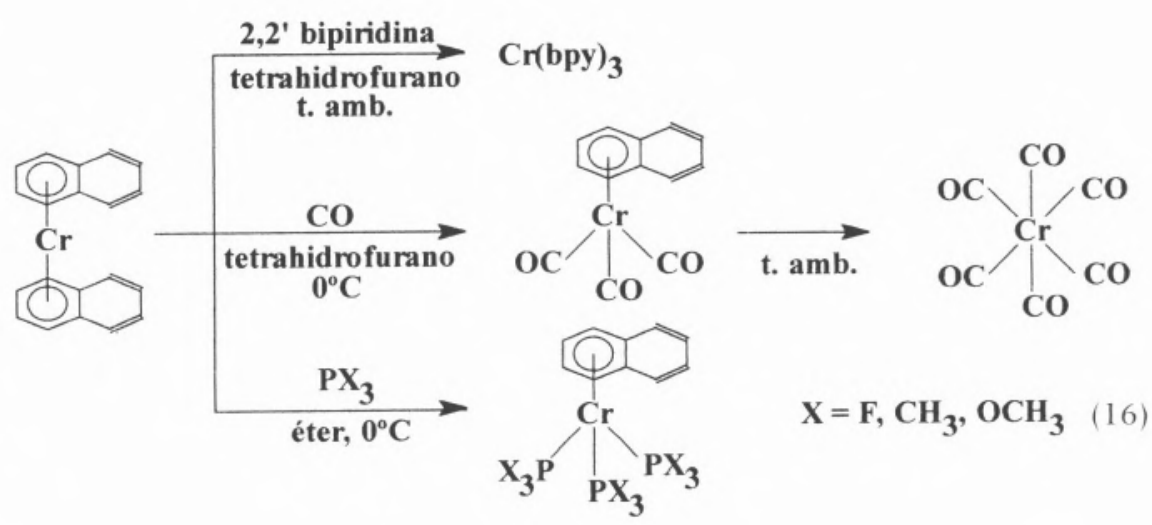


mação de cristalites metálicas, $\mathrm{M}^{*}$, de pequenas dimensões que, ao sofrerem pirólise, hidrogenação ou hidrólise, libertam hidrocarbonetos com um número de átomos de carbono inferior ao do solvente inicial [3].

Este facto indica que na sua formação esteve envolvida a ruptura de ligações C-C, formando-se fragmentos de solvente que se coordenam aos com alcanos, também é possível obter estas suspensões por co-condensação de arenos ou tetrahidrofurano com metais com os quais não formem complexos estáveis em proporções estequiométricas, como o Fe, $\mathrm{Co}$ ou $\mathrm{Ni}$.

As "lamas" assim produzidas podem ser utilizadas na preparação de complexos organometálicos (Equação 17), alguns dos quais ape-
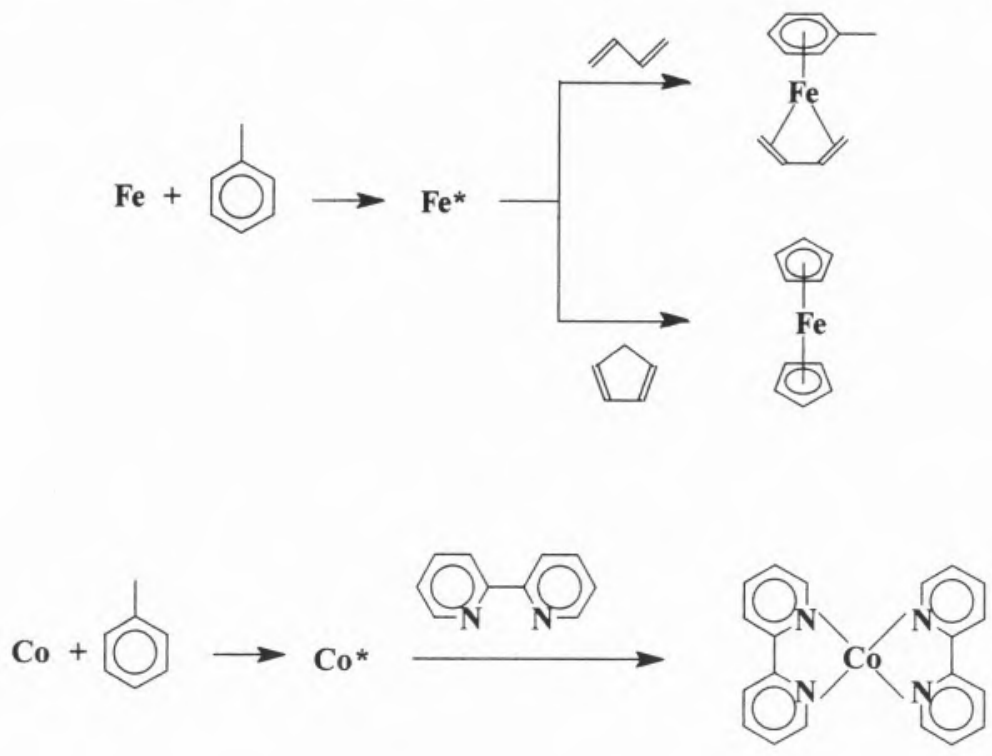

$\mathrm{Rh}+\bigcirc \rightarrow \mathrm{Rh}^{*} \underset{\mathrm{H}_{2}}{\longrightarrow}$

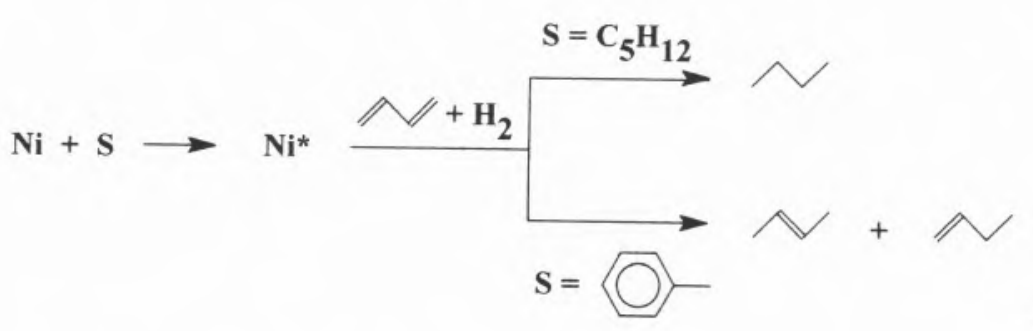

átomos metálicos, reduzindo a formação de ligações metal-metal. Este reduzido grau de ligação metal-metal vai-se reflectir na elevada área superficial apresentada pelas cristalites e na grande reactividade destas suspensões metálicas ou "lamas".

Apesar de serem mais comuns as "lamas" obtidas por co-condensação por átomos isolados, com todas as posições de coordenação livres, logo bastante reactivos, deverá ser um bom catalisador para um grande número de reacções. De entre os ensaios catalíticos efectuados por este método merecem particular referência estudos da oligomerização de butadieno (Equação 21), da isomerização de olefinas (Equação 22) e de polimerização de estireno (Equação 23) [2].

\section{7 - O MÉTODO DOS VAPORES METÁLICOS EM PORTUGAL}

Actualmente em Portugal dois grupos de investigação utilizam o Método dos Vapores Metálicos.

O primeiro a utilizar este método foi o grupo de Química Organometálica do Centro de Química Estrutural (CQE), do Instituto Superior Técnico, que, nos anos 70, adquiriu o reactor VSP-101, o primeiro reactor para MVS comercializado pela firma GV Planer Ltd.. Este reactor, do tipo rotatório, foi utilizado na preparação de catalizadores de $\mathrm{TiCl}_{4}$ e $\mathrm{MgCl}_{2}$ e na obtenção de "lamas" de magnésio. Contudo, mostrou-se bastante ineficiente, em particular no que diz respeito ao vácuo, e foi substituido por um reactor estático construido no CQE, que reteve do reactor anterior apenas o gerador de alta-tensão, e que utiliza como bomba secundária uma criobomba em lugar de uma difusora.

Com este reactor foram, até ao momento, efectuados estudos de reactividade de vapores metálicos com tiofenos, nomeadamente da sua desulfuração, e a síntese de alguns complexos organometálicos com ligandos policíclicos (Equação 24) e heterocíclicos (Equação 25) [17]:

O outro grupo de investigação que utiliza este método pertence ao Departamento de Química do Instituto de Tecnologia Nuclear, que adquiriu também à firma G.V. Planers Ltd. um reactor VSP 500, um dos modelos mais recentes, equipado com um canhão de electrões (com uma potência de $7 \mathrm{~kW}$ ) e uma fornalha de resistência (com uma potência de $2.4 \mathrm{~kW}$ ). 

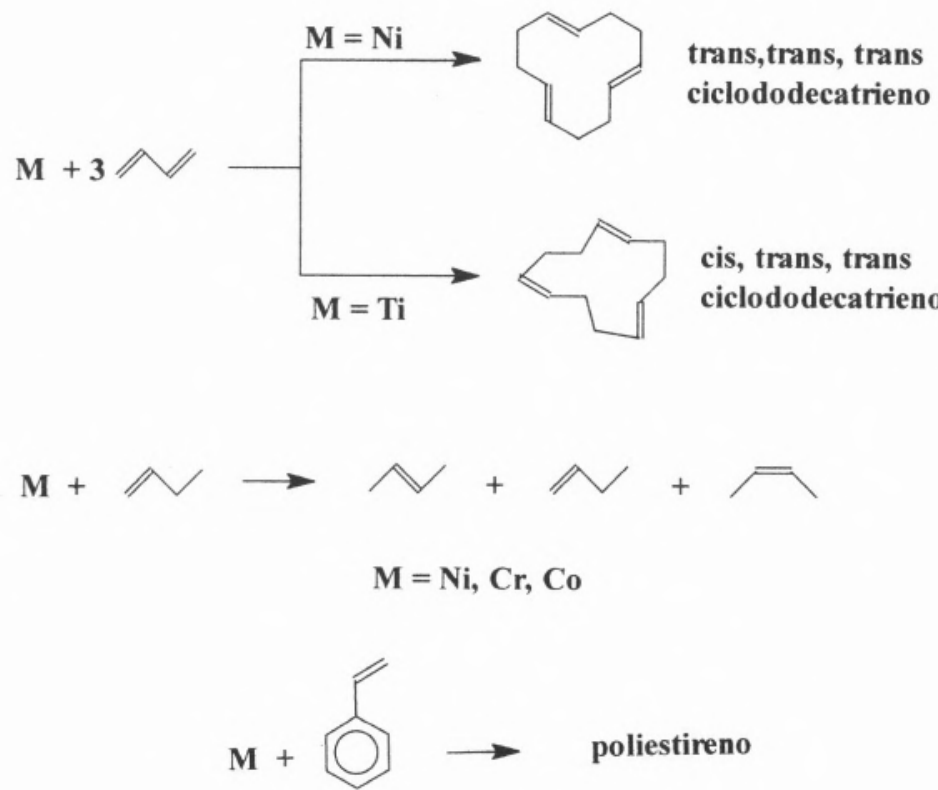

$\mathrm{M}=\mathrm{Cr}, \mathrm{Fe}, \mathrm{Ni}$
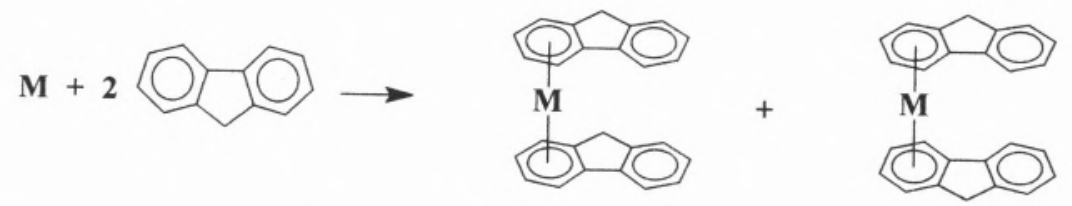

M = Ti, Cr, Mo, W

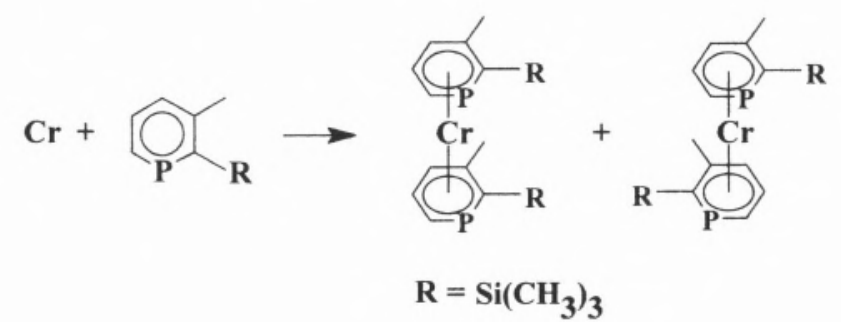

$$
\mathrm{M}+\mathrm{EtOH} \longrightarrow\left[\mathrm{M}(\mathrm{OEt})_{\mathbf{x}}\right]_{\mathbf{n}}
$$$$
\mathbf{M}=\mathbf{S m}, \mathbf{Y b} ; \mathbf{x}=\mathbf{3}
$$$$
\mathbf{M}=\mathbf{E u} ; \mathbf{x}=\mathbf{2}
$$

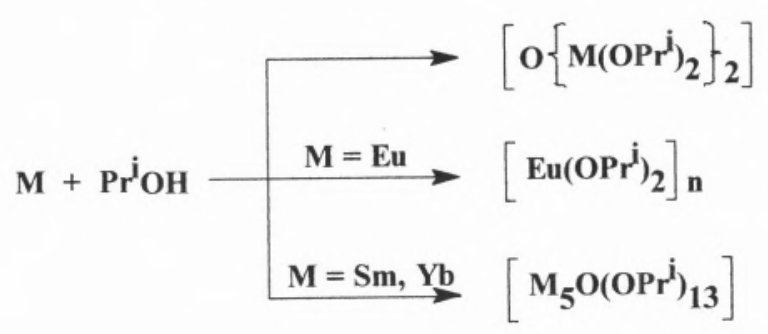

As pesquisas efectuadas por este grupo incidem, principalmente, no estudo das reacções de vapores de lantanídeos com alcoóis (Equações 26 e 27), como via alternativa para a preparação de alcóxidos destes metais por métodos em solução [18].

* Centro de Química Estrutural, Instituto Superior Técnico, Av. Rovisco Pais, 1096 Lisboa Codex

\section{BIBLIOGRAFIA}

1. P.L. Timms, 1. Chem, Soc. Chem. Comm. (1969), 1033.

2. J.R. Blackborrow, D. Young, Metal Vapour Synthesis in Organomettalic Chemistry, Verlag, New York, 1979.

3. K.J. Klabunde, Chemistry of Free Atoms and Particles, Academic Press, New York, 1980.

4. P.L. Timms, Cryochemistry, eds. M. Moskovits, G.A Ozin, capítulo 3, Wiley, New York, 1976.

5. M.J. McGlinchey, P.S. Skell, Cryochemistry, eds. M Moskovits, G.A. Ozin, capítulo 5, Wiley, New York, 1976.

6. P.L. Timms, T.W. Turney, Adv. Organomet. Chem. 15 (1977), 53.

7. U. Zenneck, Angew. Chem. Int. Ed. Engl., 29 (1990), 126.

8. M.L.H. Green, J. Organomet. Chem., 200 (1980), 119 .

9. F.G.N. Cloke, Chem. Soc. Rev. (1993), 17.

10. E. Schimdt, K.J. Klabunde, Encyclopedia of Inorganic Chemistry, eds. R. B. King, Vol. 4, 2196, John Wiley, Sussex, 1994

11. A.M.C. Moutinho, M.E.S. Silva, M. Áurea Cunha, Tecnologia de Vácuo, Universidade Nova de Lisboa, 1980.

12. Metal Atom Reactor (Catálogo de reactor de vapores metálicos), Kontes Martin \& Co, 1975

13. P.L. Timms, J. Chem. Ed., 49 (1972), 782.

14. A.J.L. Pombeiro, Técnicas e Operaçōes Unitárias em Química Laboratorial, Fundação Calouste Gulbenkian, Lisboa, 1983.

15. J.P. Leal, Química, 59 (1995), 56.

16. The NBS Tables of Chemical Thermodynamics Properties, J. Phys. Chem. Ref. Data, 11 (1982), Supplement $\mathrm{n}^{\circ} 2$.

17. F.G.N. Cloke, A.R. Dias, A.M. Galvão, J.L. Ferreira da Silva, J. Organomet. Chem., em publicação.

18. J. Carretas, A. Pires de Matos, Mat. Chem. and Phys., 31 (1992), 123. 